\title{
The Relationship Between Crowdsourcing and Consumer Power
}

\author{
Matthew Wilson \\ Central Michigan University \\ wilso6m@cmich.edu
}

\author{
Obinna Obilo \\ Central Michigan University \\ obilo1o@cmich.edu
}

\author{
Karen Robson \\ University of Windsor \\ krobson@uwindsor.ca
}

\begin{abstract}
This research investigates consumer power in the context of crowdsourcing. In a series of studies, this research explores differences in consumer perceptions of power based on whether they participate in idea crowdsourcing (in which consumers submit ideas for new offerings) or in crowd voting (in which consumers are invited to vote for various options for new offerings). This research also manipulates whether the crowdsourced ideas or votes were accepted or rejected by the firm, and provides an investigation of consumer perceptions of power. Implications for marketers in terms of optimizing the management of a crowdsourcing initiative are discussed.
\end{abstract}

\section{Introduction}

Consumers are more powerful than ever before, largely as a result of modern technologies [1]-[4]. In particular, consumer power is greatest when consumers enter into collectives [5] and harness the power in numbers. For example, some of the highly impactful ways that consumers use disruptive technologies to harness their collective power over marketers include organizing into online groups that participate in boycotts or engaging in influential blogging [6] or gathering in online forums to share reviews of products and services [7].

One way of harnessing the potential value that these consumer collectives provide is through crowdsourcing - or when firms use IT to outsource some organizational function to outsiders in an open call [8]. When engaging in crowdsourcing, firms use technologies to leverage the collective wisdom and insight of consumers, ideally creating both firm and consumer value in the process. Yet, little is known about the consumer experience of participating in crowdsourcing initiatives, particularly with respect to how they perceive their position of power when involved in crowdsourcing and how their participation, including whether or not their suggestions are heeded by the firm, impacts their relationship with the firm that solicits their involvement.

This paper investigates how consumer perceptions of power vary depending on the type of crowdsourcing initiative they participate in, and how an individual's perceived power differs based on whether the firm accepts or ignores the will of the crowd. In what follows, a review of the literature on consumer power is presented, with a focus on digitally enabled collective consumer power and crowdsourcing. Subsequently, the study design and data collection methods are outlined and the results are presented. This paper concludes with a discussion of the implications of this research and directions for future research.

\section{Power}

One of the most influential frameworks for understanding social power comes from French and Raven [9] who conceptualized several bases of power that dictate social relationships: reward power, coercive power, legitimate power, referent power, and expert power. Reward power occurs when one actor administers positive consequences or removes negative ones. For example, a consumer can reward a firm through purchasing and loyalty. Coercive power involves the ability to punish undesirable behaviors, such as when consumers post negative comments or switch to a different brand. In marketing terms these actions are commonly referred to as exit and voice [10]. Legitimate power occurs when one actor is inferior to another; in these cases, the superior actor can exercise a legitimate right to influence the inferior actor, and the inferior actor has an obligation to accept this influence. In marketing, legitimate power is exemplified when consumers successfully influence aspects of offerings such as product features or price. Referent power occurs when one actor identifies with another. For example, consumers may identify with a brand and join the brand community. Lastly, expert power, stems from information asymmetry. For example, when a consumer believes that a firm is better informed, they are more likely to accept the information or 'expertise' of the firm rather than question it. Combined, these bases determine the potential for one actor to influence or control valued resources of another actor. In the decades that have followed, this framework of power has been applied numerous times to understand the relationship between two or more parties [11], [12], including firms and 
consumers [3], [13]-[16], and has also been applied to understand consumer power in the context of crowdsourcing [17].

As noted earlier, the way consumer power is structured among these bases has changed over time, with social media leading to a drastic change in the balance of power between consumers and marketers. With this in mind, Rezabakhsh et al. adapted French and Raven's framework in order to account for the impact of the Internet and related technologies, concluding that each of the bases of power have shifted towards the consumer in the era of the Internet. This work, along with other contemporary research [18], [19] indicate that French and Raven's bases of social power continue to serve as an appropriate lens with which to interpret consumer power, and provide updated conceptualizations based on how social media and related technologies have impacted consumer power.

\subsection{Power in Crowdsourcing}

Crowdsourcing occurs when firms use information technology "to outsource any organizational function to a strategically defined population of human and nonhuman actors in the form of an open call" [8, pg. 152]. Thus, crowdsourcing is a strategy that is enabled by disruptive technologies, and that organizations implement in order to increase their exposure to ideas, knowledge, and experience, which can be used to the benefit of the organization [20]-[22]. In a marketing context, crowdsourcing is most commonly used to solicit consumer ideas or votes for new or improved offerings [23].

Research identifies crowdsourcing as a useful context with which to examine the upper limits of contemporary consumer power [5], [24]. Despite being a particularly useful context for examining consumer power, little research directly focuses on consumer power in crowdsourcing. The limited research on this topic investigates strategic concerns and unintended consequences that occur in crowdsourcing [17], [25]. Wilson et al. use the term crowd hijacking to describe situations in which crowdsourcing participants assail the initiative in an effort to push their own agenda [25]. For example, Chevrolet crowdsourced advertisements for its Tahoe model in 2006, and the crowd responded with unflattering and contemptuous commercials, highlighting the harmful environmental effects of the vehicle. Wilson et al. also identified crowdthink, which occurs when participants make a mockery out of a crowdsourcing campaign. In many cases, crowdthink begins as a humorous prank that spreads online within crowds, such as the case in which the name 'Boaty McBoatface' - which was presumably submitted as a joke - became the most popular name for a prestigious research vessel in the UK.

The risks associated with relinquishing control to the crowd are not uniform across all implementations of crowdsourcing [17]. Crowdsourcing endeavors can be classified based on whether the contributions from the crowd are objective or subjective in nature, and are filtered or aggregated [26]. These dimensions delineate four forms of crowdsourcing: crowd voting (aggregated, subjective), where the crowd votes for their favorite option from a predetermined list; idea crowdsourcing (filtered, subjective), where the crowd submits creative ideas and original content; micro-task crowdsourcing (aggregated, objective), where human workers perform small tasks as part of a larger undertaking, and; solution crowdsourcing (filtered, objective), where firms invite others to solve complex organizational problems. Using this crowdsourcing typology, Wilson theorized how the bases of social power [9] are structured in each form of crowdsourcing [17]. Specifically, Wilson posits that the degree to which power temporarily tilts in favor of the consumer, and in which form, varies depending on the type of crowdsourcing activity, with consumer power most elevated during idea crowdsourcing.

Ultimately, although previous research theorizes how power is structured in crowdsourcing, no research provides an empirical investigation into how consumers perceive their power in crowdsourcing and whether these perceptions of power do indeed vary depending on the crowdsourcing context. Yet, it is the consumers' perception of power that ultimately dictates their ability to exert control in these scenarios. To better understand how power is altered during crowdsourcing activities, this paper seeks to empirically test some of the propositions presented by Wilson. Thus, one question this research investigates is whether there are differences in how people perceive their position of power in the two most commonly employed forms of crowdsourcing in marketing: idea crowdsourcing versus crowd voting [23].

\subsection{Outcomes in Crowdsourcing}

In addition to investigating differences in consumer perceptions of power in idea crowdsourcing and crowd voting, this research takes a longitudinal approach to better understand how the decision of the firm to accept (or reject) the contributions of the crowd impacts consumers' attitudes and purchase likelihood. Previous research examining consumer collectives has revealed a number of key insights on these subjects. For example, Fuchs et al. reveal an "empowerment-product demand" effect, which occurs when consumer communities are empowered to select the offerings to be marketed by 
firms and subsequently show greater demand (and higher willingness to pay) for these products than for identical products that they did not select [27]. This finding reveals that when consumer communities are given the power to become more involved in a firm's marketing operations, they develop strong feelings of psychological ownership, which benefits firms through increased demand and positive word of mouth. This is similar to findings from other research that suggests consumers who experience greater power in the marketing function may experience a closer relationship to resultant offerings and have an increased willingness to pay for them [28]. Yet, firms sometimes opt against the will of the crowd [25], and existing literature does not provide understanding of consumer perceptions or managerial implications when firms don't honor the will of the crowd. From a practical standpoint, better understanding the impact of crowdsourcing decisions on purchase intentions or brand perceptions would be beneficial. Thus, the final research question we investigate is: what impact does accepting or rejecting the will of the crowd have on consumer perceptions of power, attitude towards the brand, and purchase likelihood? The following sections present three studies wherein we investigate perceptions of consumer power in crowdsourcing.

\section{Study 1}

\subsection{Methods}

Despite the fact that a number of papers propose that consumers are highly empowered when they become members of collectives, and particularly in the context of crowdsourcing (e.g., [5], [17], [29]), research has yet to confirm this empirically or to provide in-depth understanding of consumer power as it relates to crowdsourcing. One likely reason for this shortage of empirical research is the lack of a measurement instrument for evaluating consumer perceptions of their own power. To address this, we adopt, adapt, and validate selected components of a scale for measuring perceptions of social power [30], and utilize this scale in subsequent investigations of consumer perceptions of power when engaged in crowdsourcing.

We adapted the Perceived Social Power Scale [30] to measure consumer power in crowdsourcing. The original scale was designed to capture social power in work situations, and was based on constructs from French and Raven's theory of social power. The original wording of the scale was modified to reflect the nature of the current research context: crowdsourcing. Specifically, we focused on crowd voting and idea crowdsourcing. This decision was made for two reasons. First, both crowd voting and idea crowdsourcing involve subjective contributions [26]. Participants provide personal opinions, beliefs, and perceptions in their responses, which are important to firms but can also lead to unintended consequences [25]. This is unlike microtask and solution crowdsourcing where contributions can be objectively evaluated as true or false, correct or incorrect [26]. Second, idea crowdsourcing and crowd voting are the most common types of crowdsourcing to be implemented in marketing [23].

We sought to assess the reliability and validity of the modified scale for the current context by utilizing the procedures put forth by Gerbing and Anderson [31]. We collected the validity/reliability assessment data by presenting respondents with a scenario where they were asked to aid a fictional cereal company in developing new flavors and new packaging design ideas. Consumer goods companies employ crowdsourcing techniques across their strategic initiatives more than other company types [32], [33]. As such, we simulated a consumer goods crowdsourcing endeavor in this research. After going through the idea-generation exercise, we prompted respondents to respond to the 7point Likert type items of the modified power scale, with the goal being for them to reference perceptions of their power relative to the firm during the exercise.

We gathered a sample of 283 adult respondents via Amazon Mechanical Turk (Mturk). Mturk has been shown to be a reliable source for conducting experimental data [34] and its participant pool provides better representation of the general population than typical convenience samples [35]. We appealed to participants for honest responses and used attention checks in the survey to help obtain quality responses. After the data collection, potentially dishonest or inattentive responses were identified and removed. In addition to removing respondents that failed the attention check questions, we identified and eliminated outliers via nonsensical content provided in the idea generation form. The resulting sample consisted of 257 respondents (48\% Male, 52\% Female; 18-24 yrs, 14\%; $25-34$ yrs, 36\%; 35-44 yrs, 22\%; 45-54 yrs, 17\%; 55 yrs and above, $11 \%$ ).

\subsection{Results}

We constrained the data to the factor structure posited by Imai [30] via a confirmatory factor analysis (CFA) to assess the model's fit, reliability, and validity using IBM AMOS 24.0. The congeneric model produced a $\chi^{2}$ value of 458.4 and 84 degrees of freedom. Most of the standardized maximum likelihood loadings were over 0.6 , but a few proved to be problematic. Examining the fit indices for the model, we noted a comparative fit index (CFI) of .80 and a root mean 
square error of approximation (RMSEA) of .137; together, these indices suggest poor fit according to the guidelines provided by Hair et al. [36]. The high degree of covariance between the three power constructs (reward, legitimate, and expert) in the current context greatly affected the observed lack of fit. This is not unprecedented, as previous research has addressed this problem; Brill argued that operationalizing French and Raven's power bases would be a difficult task, as the power bases are not necessarily mutually exclusive [37]. We determined that since only the coercive and expert power bases are of interest in this research we would subject those sub-scales to a CFA independently. In this new assessment, the congeneric model produced a $\chi^{2}$ value of 19.3 and 8 degrees of freedom. The standardized maximum likelihood loadings were all over 0.6. Examining the fit indices for the model, we noted a CFI of .98 and a RMSEA of .077; together, these indices suggest good fit according to the guidelines provided by Hair et al. [36] , for samples with over 200 respondents and under 30 observed variables. Having satisfied the requirements for fit, the measurement model was next assessed for reliability, convergent validity, and discriminant validity.

Construct reliability values above 0.7 are ideal [36]; the construct reliabilities were: Expert Power (.85), Coercive Power (.82), thus satisfying the construct reliability requirement. Convergent validity was assessed by examining the extracted construct reliabilities and item loadings on to their respective factors [36]. All the factor loadings were significant ( $p$ $<0.001$ ), and the construct reliability estimates (shown above) all exceeded 0.7 ; taken together, these observations suggest convergent validity for the measurement model.

Next, discriminant validity was assessed by comparing the squared correlation estimate between the latent constructs (Expert Power and Coercive Power), with the variance extracted for each construct. To pass the discriminant validity requirement, the variance extracted for a construct must exceed the squared interconstruct correlation shared between that construct and all other constructs within the model [38]. The squared construct correlation between the constructs was 0.07 ; comparing this value to the variance extracted for each construct (Expert Power (.66), Coercive Power (.61)), we noted that the discriminant validity requirement was achieved. Having passed the requirements for convergent validity, discriminant validity, and with all construct reliability values being over 0.7 , we can confidently state that we have a reliable and valid measurement model.

\section{Study 2}

The first question we sought to answer in this research was whether there are differences in how people perceive their position of power depending on whether they are participating in idea crowdsourcing or crowd voting. Specifically, based on the conceptualization of the bases of power outlined by Wilson [17], we examined differences in perceptions of expert and coercive power between participants of crowd voting and idea crowdsourcing. Wilson posits that because of the open-ended nature of idea crowdsourcing, there is more opportunity for consumers to hijack the initiative and push their own agenda, coercing the firm to adopt their ideas; this is in contrast to crowd voting where consumers generally choose from a given pre-selected or pre-approved set of options, which confines responses and limits coercive power. Likewise, in idea crowdsourcing, firms rely on the creativity and expertise of consumers in coming up with inventive and appealing ideas. Conversely, in crowd voting, firms merely seek the most popular selections or the will of the people.

Our goal was to assess consumers' perceptions of their expert and coercive power in these crowdsourcing scenarios, and thus we deemed an experimental design to be the best way to simulate the scenario before collecting the consumers' data on their power perceptions. Experiments are the best choice in this research as they allow manipulation of the different crowdsourcing contexts (crowd voting and idea crowdsourcing) and outcomes and allow testing of consumers responses to the scenarios they are exposed to.

\subsection{Methods}

We conducted a 1-factor (1 (crowdsourcing type) $\mathrm{x}$ 2 (idea crowdsourcing vs. crowd voting)) betweensubjects experimental design in study 2. Once respondents clicked on the survey link and responded to a consent document, they were randomly presented with either an idea crowdsourcing or a crowd voting scenario. In the idea crowdsourcing scenario, respondents were asked to provide ideas for: new cereal ingredients, names, box designs, and other innovations for a cereal manufacturer. Responses in this scenario were openended, giving participants the opportunity to provide detailed ideas. Respondents in the crowd voting scenario were asked the same questions but had to pick answers from a pre-generated list of five options. Following the experimental scenario, respondents answered a series of questions regarding their power 
perceptions, attitude towards the brand, and purchase likelihood.

A sample of 275 U.S. adult respondents was sought via Amazon Mechanical Turk. Inattentive participants and outliers were identified and removed from the data set using the same procedure as in Study 1 . The resulting sample consisted of 250 respondents (55\% Male, $45 \%$ Female; 18-24 yrs, 13\%; 25-34 yrs, 44\%; 35-44 yrs, $24 \%$; $45-54 \mathrm{yrs}, 11 \%$; $55 \mathrm{yrs}+, 8 \%$ ).

The power scale adapted in Study 1 was used to capture consumers' perception of their power in this study, specifically relating to expert and coercive power bases. Attitude towards the brand refers to the respondents' positive or negative overall reaction to the cereal brand they are providing with ideas. This was measured by asking the subjects to respond to a statement regarding the brand, followed by four semantic differentials (high quality-low quality, goodbad, likable, not likable, pleasant-unpleasant) on a seven-point scale [39], [40]. Purchase likelihood was measured using a single item that asked respondents their likelihood of purchasing a product from the brand. We employed MANOVA to assess the mean differences across the dependent variables.

\subsection{Results}

The MANOVA across the dependent variables for both crowdsourcing types (crowd voting and idea crowdsourcing) produced an $\mathrm{F}$ value of $2.571(p<.05)$ thus, we infer that across crowdsourcing types, there is a difference in at least one of the dependent variables. Examining each of the conditions individually via a univariate ANOVA, we note that subjects in the idea crowdsourcing scenario display higher levels of perceived coercive power than their crowd voting counterparts (M: 2.21 vs. 1.80$) \mathrm{F}=4.58(p<0.05)$. Idea crowdsourcing subjects do not display significantly higher levels of perceived expert power than their crowd voting counterparts ( $\mathrm{M}: 4.63$ vs. 4.77$) \mathrm{F}=0.897(p=$ $0.345)$.

\section{Study 3}

Study 3 builds on study 2 by exploring consumer power longitudinally. We assess what effects firms' responses to the results of crowdsourcing activities have on consumers' perception of power and on their relationships with the firm. The motivation for this inquiry stems from the fact that the results of any crowdsourcing endeavor are not immediately revealed. Rather, firms carry out these endeavors (at time 1) and announce the outcome of the crowdsourcing campaign at a later date (time 2) once a sufficient number of responses from the crowd have been collected. Most research on crowdsourcing looks at one point in time only, and does not consider the outcome of the crowdsourcing endeavor [41]. Yet, the outcome of crowdsourcing is particularly relevant in terms of consumer power. Firms can respond to crowdsourcing initiatives by adopting an empowered or a traditional viewpoint (Fuchs et al. 2010). In the empowered viewpoint, firms simply accept the will of the consumers as indicated by the results of the crowdsourcing initiative. Contrarily, in the traditional viewpoint, firms assess the results of the crowdsourcing but still maintain control over the final decisions (i.e. they can choose to accept or reject the will of the crowd). Wilson et al. (2017) posit that rejecting the will of the crowd can be detrimental to consumers' perceived power as well as to their relationships with the erring firm. If the firm rejects consumers' ideas, consumers might feel less empowered than they originally felt when participating in the crowdsourcing initiative (Fuchs et al. 2010). In particular, the impact of rejecting the will of the crowd could impact perceived expert power, as rejecting the will of the crowd can be taken as a sign that despite something being popular with the crowd, the firm "knows better". We also tested if consumer's initial perceptions of expert power, purchase likelihood, and attitude towards the brand were altered from the time they participated until the outcome was announced.

\subsection{Methods}

We used a 2 (accept vs. reject) x 2 (time 1 vs. time 2 ) experimental design in this study. This experiment is designed as a follow-up to Study 2 and as such the participants are the same in both studies. Respondents were informed of the follow-up nature of this study and were randomly presented with a statement indicating that their contribution was the most popular and that the firm had accepted it (accept condition), or that their contribution was the most popular but that the firm had nevertheless decided to go in a different direction (reject condition). We then assessed the manipulation by asking respondents if their contributions with were accepted or rejected. Respondents then answered a series of questions regarding their power perceptions, attitudes towards the brand, and purchase likelihood.

The same sample of 250 respondents from Study 2 were sought out to participate again in Study 3. The longitudinal sample resulted in a $64 \%$ response rate with 160 respondents $(53 \%$ Male, $47 \%$ Female; $18-24$ yrs, 9\%; 25-34 yrs, 41\%; 35-44 yrs, 25\%; 45-54 yrs, 16\%; 55 yrs and above, $9 \%$ ).

Consumers' perceptions of their coercive and expert power, attitudes towards the brand, and purchase likelihood were captured in the same way as in the 
previous studies. We also employed multivariate analysis of variance to test the data in this study.

\subsection{Results}

The MANOVA across the dependent variables for acceptance/rejection produced an $\mathrm{F}$ value of $6.825(p<$ $.05)$ thus, we infer that there is a difference in at least one of the dependent variables. Examining each of the conditions individually via univariate ANOVAs, we note that subjects in the "accepted" condition display higher levels of perceived expert power (M: 4.9 vs. 4.3) $\mathrm{F}=8.474(p<0.05)$, attitude towards the brand (M: 6.1 vs. 5.5) $\mathrm{F}=20.28(p<0.05)$, and purchase likelihood (M: 5.6 vs. 4.6$) \mathrm{F}=16.21(p<0.05)$ than their "rejected" condition counterparts.

Study 3 explores the subjects longitudinally. Specifically, it explores whether between a time 1 (when subjects first give their suggestions to the firm) and a time 2 (when the firms reveals whether it accepts or rejects the suggestion), acceptance by the firm will lead to a change in subjects' perceived expert power, attitude towards the brand, and purchase likelihood. The MANOVA across all dependent variables of interest produced an $\mathrm{F}$-value of $3.814(p<0.05)$. Examining each of the conditions individually via univariate ANOVAs, we note that subjects' perceived expert power (M: 4.7 vs. 4.9$) \mathrm{F}=7.15(p<0.05)$ and purchase likelihood (M: 5.3 vs. 5.6) $\mathrm{F}=4.26(p<0.05)$, increase significantly between times 1 and 2 . Subjects' attitudes towards the brand (M: 6.2 vs. 6.1) $\mathrm{F}=0.183(p=0.670)$ did not result in significant changes.

Study 3 also explores whether, in cases where the will of the crowd is rejected, there are differences in subjects' perceived power, attitudes towards the brand, and purchase likelihood between time 1 (when subjects give their suggestions to the firm) and time 2 (when the firms rejects the will of the crowd). The MANOVA across all dependent variables of interest produced an $\mathrm{F}$ $=4.550(p<.05)$. Examining each of the conditions individually via univariate ANOVAs, we note that subjects' attitude towards the brand (M: 6.0 vs. 5.2$) \mathrm{F}=$ $18.922(p<0.05)$ and purchase likelihood (M: 5.1 vs. 4.6) $\mathrm{F}=3.61(p=0.05)$ decrease significantly between times 1 and 2. Subjects perceived expert power (M: 4.5 vs. 4.3) $\mathrm{F}=3.53(p=0.065)$ did not change significantly.

\section{Discussion}

The results of the experiments conducted in this paper add to the body of research suggesting that consumer perceptions of power have been impacted by disruptive technologies, and provide a novel and indepth investigation of how they are impacted in the context of crowdsourcing. Specifically, results indicate that consumer perceptions of power depend on the nature of a crowdsourcing exercise. Consumers report elevated levels of perceived coercive power when involved in idea crowdsourcing compared to crowd voting. This supports the argument from Wilson [17] who theorized that the open nature of idea crowdsourcing facilitates the ability of participants to cause trouble for firms by submitting ideas which advance their own agenda rather than ideas which genuinely consider the interests of the firms. However, participants did not report elevated expert power in idea crowdsourcing compared to crowd voting. There are several potential explanations for this finding, one of which is the nature of the crowdsourcing scenarios (new product development or voting for a cereal brand) used in our experiments. We chose to use a new product development scenario for a consumer goods brand as these types of companies and crowdsourcing endeavors are commonplace. Although this scenario has the benefit of being realistic, it was the only context investigated. It is possible that participant ideas and votes regarding breakfast cereal marketing may simply have failed to provide a context in which participants expertise was sufficiently engaged. Perceptions of expert power are likely to be higher when participants are engaged in creative endeavors or activities where they feel that they can provide novel input [17]. Thus, although participants were able to provide open-ended ideas regarding various topics for a cereal company, it is conceivable that this activity did not rise to a level necessary to elicit feelings of expertise.

Similarly, some participants may have deemed that their personal knowledge of cereals inadequate to qualify them as having any expertise. Research suggests that consumers who participate in crowdsourcing often fail to understand a number of key business concerns related to new product development, such as the costs associated with implementing ideas and, importantly, the potential of their contributions to generate sales. [42] That is, participants may simply have not understood their own expertise. Relatedly, Fuchs et al. [27] identify a boundary condition for their empowerment productdemand effect, noting that it diminishes when consumers feel they lack the necessary capabilities to make appropriate decisions. Future research should explore whether other more complex crowdsourcing tasks lead to differences in perceived expert power. This finding would reveal a boundary condition of the conceptualizations made by Wilson [17], and would further illuminate how consumer perceptions of power in crowdsourcing depend on the context.

This research provides new insight into how consumers react based on whether or not the firm proceeded with the acknowledged 'will of the crowd'. We reveal that participants react more favorably 
towards the firm and perceive that they possess elevated expert power when the crowd's ideas are enacted rather than disregarded. This finding is supported by previous research, in which the act of participating in various marketing processes led to feelings of ownership and empowerment, as well as to positive feelings toward the brand's products [27]. In the current research, both attitude toward the brand and purchase likelihood are higher for individuals in a crowd whose ideas were accepted; these findings are particularly relevant for firms when they are faced with outcomes of crowdsourcing campaigns that they did not foresee or are not aligned with their objectives.

\section{Conclusion}

Power dictates how humans act in social contexts, including as consumers. This research empirically investigates consumer power in the context of the digitally enabled, disruptive process of crowdsourcing. In doing so, this paper makes two key contributions to the literature. First, it validates a scale for measuring perceptions of expert and coercive power in the context of crowdsourcing. Second, it addresses a gap in understanding how consumers perceive their power in relation to marketers when participating in crowdsourcing campaigns, and how consumers may react in terms of purchase likelihood and attitudes towards the brand when the brand disregards the will of the crowd. The findings from this paper contribute to the body of knowledge on consumer power and can be used by practitioners who wish to tap into the value of crowds.

\section{References}

[1] J. Füller, H. Mühlbacher, K. Matzler, and G. Jawecki, "Consumer Empowerment Through Internet-Based Co-creation," Journal of Management Information Systems, vol. 26, no. 3, pp. 71-102, Dec. 2009, doi: 10.2753/MIS0742-1222260303.

[2] L. Pitt, P. Berthon, R. Watson, and G. Zinkhan, "The Internet and the birth of real consumer power," Business Horizons, vol. 45, no. 4, pp. 7-14, Jul. 2002.

[3] B. Rezabakhsh, D. Bornemann, U. Hansen, and U. Schrader, "Consumer Power: A Comparison of the Old Economy and the Internet Economy," J Consum Policy, vol. 29, no. 1, pp. 3-36, Mar. 2006.

[4] L. Wathieu, "Consumer control and empowerment: A primer," Marketing Letters, vol. 13, no. 3, pp. 297305, 2002.

[5] L. Labrecque, J. vor dem Esche, C. Mathwick, T. Novak, and C. Hofacker, "Consumer power: Evolution in the digital age," Journal of Interactive Marketing, vol. 27, no. 4, pp. 257-269, 2013.

[6] G. Kerr, K. Mortimer, S. Dickinson, and D. Waller, "Buy, boycott or blog: Exploring online consumer power to share, discuss and distribute controversial advertising messages," European Journal of Marketing, vol. 46, no. 3/4, pp. 387-405, 2012.

[7] T. Hennig-Thurau, K. Gwinner, G. Walsh, and D. Gremler, "Electronic word-of-mouth via consumeropinion platforms: what motivates consumers to articulate themselves on the internet?," Journal of interactive marketing, vol. 18, no. 1, pp. 38-52, 2004.

[8] J. Kietzmann, "Crowdsourcing: A revised definition and an introduction to new research," Business Horizons, vol. 60, no. 2, pp. 151-153, 2017.

[9] J. French and B. Raven, "The bases of social power," Classics of organization theory, vol. 7, 1959.

[10] A. Hirschman, Exit, voice, and loyalty: Responses to decline in firms, organizations, and states, vol. 25. Harvard university press, 1970.

[11] S. Elias, "Fifty years of influence in the workplace: The evolution of the French and Raven power taxonomy," Journal of Management History, vol. 14, no. 3, pp. 267-283, 2008.

[12] W. Erchul and B. Raven, "Social power in school consultation: A contemporary view of French and Raven's bases of power model," Journal of School Psychology, vol. 35, no. 2, pp. 137-171, 1997.

[13] P. Busch and D. Wilson, "An Experimental Analysis of a Salesman's Expert and Referent Bases of Social Power in the Buyer-Seller Dyad," Journal of Marketing Research, vol. 13, no. 1, pp. 3-11, 1976.

[14] F. R. Dwyer, P. H. Schurr, and S. Oh, "Developing Buyer-Seller Relationships," Journal of Marketing, vol. 51, no. 2, pp. 11-27, 1987.

[15] M. Richins, "An Analysis of Consumer Interaction Styles in the Marketplace," Journal of Consumer Research, vol. 10, no. 1, pp. 73-82, 1983.

[16] J. Taylor and A. Woodside, "Effects on Buying Behavior of References to Expert and Referent Power," Journal of Social Psychology, vol. 117, no. 1, p. 25, Jun. 1982.

[17] M. Wilson, "Where is the power in numbers? Understanding firm and consumer power when crowdsourcing," Business Horizons, vol. 61, no. 4, pp. 545-554, Jul. 2018, doi: 10.1016/j.bushor.2018.03.004.

[18] D. Rucker, A. Galinsky, and D. Dubois, "Power and consumer behavior: How power shapes who and what consumers value," Journal of Consumer Psychology, vol. 22, no. 3, pp. 352-368, 2012.

[19] O. Merlo, G. J. Whitwell, and B. A. Lukas, "Power and marketing," Journal of Strategic Marketing, vol. 12, no. 4, pp. 207-218, 2004.

[20] L. Erickson, I. Petrick, and E. Trauth, "Hanging with the right crowd: Matching crowdsourcing need to crowd characteristics.," Proceedings of the 18th Americas Conference on Information Services, 2012.

[21] R. V. Kozinets, A. Hemetsberger, and H. J. Schau, "The wisdom of consumer crowds: Collective innovation in the age of networked marketing," Journal of Macromarketing, vol. 28, no. 4, pp. 339354, 2008.

[22] E. Von Hippel, Democratizing innovation. MIT press, 2005. 
[23] C. Terwiesch and Y. Xu, "Innovation contests, open innovation, and multiagent problem solving," Management science, vol. 54, no. 9, pp. 1529-1543, 2008.

[24] H. Bachouche and O. Sabri, "Empowerment in marketing: synthesis, critical review, and agenda for future research," AMS Review, pp. 1-20, 2019.

[25] M. Wilson, K. Robson, and E. Botha, "Crowdsourcing in a time of empowered stakeholders: Lessons from crowdsourcing campaigns," Business Horizons, vol. 60, no. 2, pp. 247-253, 2017.

[26] J. Prpić, P. P. Shukla, J. H. Kietzmann, and I. P. McCarthy, "How to work a crowd: Developing crowd capital through crowdsourcing," Business Horizons, vol. 58, no. 1, pp. 77-85, Jan. 2015.

[27] C. Fuchs, E. Prandelli, and M. Schreier, "The Psychological Effects of Empowerment Strategies on Consumers' Product Demand," Journal of Marketing, vol. 74 , no. 1 , pp. $65-79$, Jan. 2010 , doi: 10.1509/jmkg.74.1.65.

[28] M. Sawhney, G. Verona, and E. Prandelli, "Collaborating to create: The Internet as a platform for customer engagement in product innovation," Journal of interactive marketing, vol. 19, no. 4, pp. 4$17,2005$.

[29] O. A. Acar and S. Puntoni, "Customer empowerment in the digital age," Journal of Advertising Research, vol. 56, no. 1, pp. 4-8, 2016.

[30] Y. Imai, "The relationship between perceived social power and the perception of being influenced," Japanese Psychological Research, vol. 31, no. 3, pp. 97-107, 1989.

[31] D. W. Gerbing and J. C. Anderson, “An updated paradigm for scale development incorporating unidimensionality and its assessment," Journal of marketing research, vol. 25, no. 2, pp. 186-192, 1988.

[32] S. Djelassi and I. Decoopman, "Customers' participation in product development through crowdsourcing: Issues and implications," Industrial Marketing Management, vol. 42, no. 5, pp. 683-692, 2013.

[33] R. Hopkins, What is Crowdsourcing? A Guide to Open Innovation and Crowdsourcing, P. Sloane (Ed.), A guide to open innovation and Crowdsourcing. Kogan Page Limited, Philadelphia, PA, 2011.

[34] J. K. Goodman, C. E. Cryder, and A. Cheema, "Data collection in a flat world: The strengths and weaknesses of Mechanical Turk samples," Journal of Behavioral Decision Making, vol. 26, no. 3, pp. 213224, 2013.
[35] M. Buhrmester, T. Kwang, and S. D. Gosling, "Amazon's Mechanical Turk: A new source of inexpensive, yet high-quality, data?," Perspectives on psychological science, vol. 6, no. 1, pp. 3-5, 2011.

[36] J. F. Hair, B. J. Babin, B. Black, R. E. Anderson, and R. L. Tatham, Multivariate Data Analysis, 6th Edition, 6th ed. Pearson, 2006. Accessed: Dec. 17, 2018. [Online]. Available: https://www.pearson.com/us/highereducation/product/Hair-Multivariate-Data-Analysis6th-Edition/9780130329295.html

[37] J. E. Brill, "Scales to measure social power in a consumer context," ACR North American Advances, 1992.

[38] C. Fornell and D. F. Larcker, "Evaluating Structural Equation Models with Unobservable Variables and Measurement Error," Journal of Marketing Research, vol. 18, no. 1, pp. 39-50, 1981, doi: 10.2307/3151312.

[39] W. K. Darley and R. E. Smith, "Advertising claim objectivity: Antecedents and effects," Journal of Marketing, vol. 57, no. 4, pp. 100-113, 1993.

[40] M. P. Gardner, "Mood states and consumer behavior: A critical review," Journal of Consumer research, vol. 12, no. 3, pp. 281-300, 1985.

[41] B. Schemmann, A. M. Herrmann, M. M. Chappin, and G. J. Heimeriks, "Crowdsourcing ideas: Involving ordinary users in the ideation phase of new product development," Research Policy, vol. 45, no. 6, pp. 1145-1154, 2016.

[42] Y. Huang, P. Vir Singh, and K. Srinivasan, "Crowdsourcing new product ideas under consumer learning," Management science, vol. 60, no. 9, pp. 2138-2159, 2014.

[43] H. S. Christensen, M. Karjalainen, and L. Nurminen, "Does crowdsourcing legislation increase political legitimacy? The case of Avoin Ministeriö in Finland," Policy \& Internet, vol. 7, no. 1, pp. 25-45, 2015.

[44] S. Pongsakornrungsilp and J. E. Schroeder, "Understanding value co-creation in a co-consuming brand community," Marketing Theory, vol. 11, no. 3, pp. 303-324, 2011.

[45] H. J. Schau, A. M. Muñiz Jr, and E. J. Arnould, "How brand community practices create value," Journal of marketing, vol. 73, no. 5, pp. 30-51, 2009.

[46] J. Füller, H. MüHlbacher, K. Matzler, and G. Jawecki, "Consumer empowerment through internet-based cocreation," Journal of management information systems, vol. 26, no. 3, pp. 71-102, 2009. 